Institute for Research on Poverty

Discussion Paper no. 1024-93

\title{
Using Survey Participants to Estimate the Impact of Nonparticipation
}

\author{
I-Fen Lin \\ Department of Sociology \\ University of Wisconsin-Madison \\ Nora Cate Schaeffer \\ Department of Sociology \\ Institute for Research on Poverty \\ University of Wisconsin-Madison
}

November 1993

This research was supported by grants from the National Institute of Child Health and Human Development (NICHD) (HD-24571); the Office of the Assistant Secretary for Planning and Evaluation, U.S. Department of Health and Human Services (91ASPE236A); and the University of Wisconsin Graduate School. Computing support came from the Center for Demography and Ecology, which receives core support from the Center for Population Research of NICHD (HD-5876). The opinions expressed in the paper are our own and do not necessarily reflect those of the sponsoring agencies. 


\begin{abstract}
The authors evaluate the effectiveness of two models often used to measure the extent of nonparticipation bias in survey estimates. The first model establishes a "continuum of resistance" to being surveyed, placing people who were interviewed after one phone call on one end and nonparticipants on the other. The second assumes that there are "classes" of nonparticipants and that similar classes can be found among participants; it identifies groups of participants thought to be like nonparticipants and uses them as "proxies" to estimate the characteristics of nonparticipants. The authors use these models to examine how accurately they estimate the characteristics of nonparticipants and the impact of nonparticipation on survey estimates of means of child support awards and payments in Wisconsin. They find that neither model detects the true extent of nonparticipation bias.
\end{abstract}




\section{Using Survey Participants to Estimate the Impact of Nonparticipation}

Whether nonparticipation biases estimates of means and other parameters from sample surveys depends on how greatly nonparticipants differ from participants and on the number of nonparticipants relative to the sample size. But the effect of nonparticipation on sample survey estimates is difficult to describe in any particular case because researchers rarely have information about nonparticipants and, in addition, methods to adjust for nonparticipation quickly become complex (e.g., Madow, Olkin, and Rubin 1983). For these reasons, there has been recurring interest in devising a simple, ad hoc method for estimating how participants and nonparticipants differ from each other and then using this information to obtain at least rough estimates of the size and direction of nonparticipation bias in survey estimates of means and proportions. Two of the ad hoc methods that have been suggested use different underlying models of the relationship between participants and nonparticipants. One method assumes that there is a "continuum of resistance." This model places persons who were interviewed on the first contact on one end of the continuum and nonparticipants on the other (Filion 1976;

Fitzgerald and Fuller 1982). A second method assumes that there are underlying "classes" of nonparticipants and that similar classes can be found among survey participants. The model identifies groups of participants thought to be like nonparticipants and uses them as "proxies" to estimate the characteristics of nonparticipants (O’Neil 1979; Stinchcombe, Jones, and Sheatsley 1981; Smith 1984). We briefly review the assumptions underlying these two approaches and then evaluate their likely success using data from a source external to a sample survey. ${ }^{1}$ 


\section{TWO MODELS RELATING PARTICIPANTS AND NONPARTICIPANTS}

Methods based on the "continuum-of-resistance" model assume that people who need more calls or contacts to complete an interview are more like nonparticipants than are people who are interviewed with fewer calls or contacts. A justification of this model is that people who require more contacts to be interviewed would have been nonparticipants if data collection had been stopped earlier. In applications of this model, researchers have treated nonparticipants as a homogeneous group and used survey estimates based on those who are interviewed in the final contacts to infer the characteristics of nonparticipants. Researchers have usually chosen the total number of calls or contacts as an indicator of the level of effort required to obtain an interview (Hawkins 1975; Platek, Singh, and Tremblay 1978; Dunkelberg and Day 1973; Fitzgerald and Fuller 1982; Thomsen and Siring 1983; Traugott 1987).

Unlike the continuum-of-resistance model, methods based on a "classes" model divide nonparticipants into several classes and assume that these classes are also represented among participants. Using the classes model, researchers might simply divide participants into two groups, such as cooperative respondents (or amenables) and temporary refusers (or resistors)--those who at first refused to be interviewed but later were persuaded to participate (O’Neil 1979; Smith 1984). By assuming that final refusers and temporary refusers are similar, one can then estimate the impact of refusals on survey estimates of means and proportions. This method can be extended, for example, by differentiating persons who cannot be contacted during the survey from refusers, and then using respondents who needed more calls before a contact to estimate the characteristics of persons who are not contacted (Stinchcombe et al. 1981). If such assumptions are valid, the method and its extensions could be used to obtain a rough estimate of nonparticipation bias for a wide range of variables, such as income or attitudes for which information about nonparticipants is rarely available. 
Past applications of these ad hoc methods, based on either the continuum-of-resistance or classes model, vary in how they treat the diverse reasons for nonparticipation, but do not treat these reasons very systematically. In general, nonparticipation may result because selected persons are not located, are located but are not contacted for an interview, or are contacted but are unavailable for an interview because of illness or for other reasons. Selected persons may also refuse to be interviewed, or interviewers may fail to contact them before the field period of a survey is over. Which of these sources of nonparticipation are relevant in a particular case depends on the study's design and on the field procedures (Groves 1983, p. 62). For example, in an area probability design with random selection of a respondent within a household, households are randomly selected, and one eligible household member is then chosen for the sample. In this design the household is easily located, but selecting an eligible respondent may be impossible if interviewers cannot contact any household member. In a random-digit dialing (RDD) design, contacting a potential sample unit is an issue. An unanswered telephone may ring in a household or in a business or be unassigned. In a list sample or panel study design, nonparticipation may also result from failing to locate the sample members because of a lack of information about the person's current address or telephone number. Because these ad hoc methods for estimating the impact of nonparticipation require indicators derived from features of a study design or field procedures--such as indicators of the level of effort required to obtain an interview--implementing the method requires considering a specific design, and it is possible that the success of an application depends on how an indicator is chosen and implemented.

The study design affects the plausibility of a model of a continuum-of-resistance in two different ways. One issue arises when selecting an indicator of the level of effort required to obtain an interview, particularly when the study design makes several reasons for nonparticipation relevant. Depending on the study design, whether or not a continuum of resistance appears may depend on how one measures resistance or the level of effort required to obtain an interview. For instance, some 
researchers have found that, compared with the age distribution in their final samples, older people were likely to be overrepresented and younger people underrepresented in the first few calls (Hawkins 1975, p. 468; Fitzgerald and Fuller 1982, p. 13; Dunkelberg and Day 1973, p. 162). This occurs because elderly people in household samples were initially easier to contact, but overall they were more likely to refuse than were younger people; on the other hand, although it took more effort to contact younger people, once contacted, they were more likely to cooperate than were elderly people (Fitzgerald and Fuller 1982, p. 12). Thus, using the total number of calls as the indicator of resistance may confound the effort to locate and the effort to persuade a potential respondent in household samples that require households to be contacted before a respondent is selected.

Second, the continuum-of-resistance model requires the assumption that there is a monotonic relationship between a variable and the effort required to obtain an interview. However, this assumption may or may not be true in a particular study. Given the variety of variables in which researchers are interested, and the heterogeneity of nonparticipants at any given time, one could never be sure which variables had a meaningful relationship with the level of effort required to obtain an interview. For example, Thomsen and Siring (1983) in a Norwegian Fertility Study found that the number of contacts made before an interview was obtained was inversely proportional to the average number of live births (p. 37), presumably because the number of children is associated with the likelihood someone is at home. But Ellis, Endo, and Armer (1970, pp. 106-107) found that means for the variables they examined were not monotonically related to level of effort, even though they did find that, overall, respondents who returned questionnaires with regular follow-up efforts differed from those who needed special efforts.

Unlike the model of a continuum-of-resistance, the classes model does explicitly consider how study design affects nonparticipation, by dividing nonparticipants into different groups, such as those refuse or who are difficult to contact or locate. Although there may be considerable interviewer 
variation in classifying types of refusal, researchers can still relatively easily identify respondents who refused the interview but later were converted to use in estimating means for final refusers. But identifying other categories of participants who are like nonparticipants requires indicators of the level of effort needed to obtain the interview, which are also problematic for this model. Researchers may lack a precise indicator to identify groups, such as those who are difficult to locate or to contact, for use in estimating the characteristics of nonparticipants who are never located or contacted.

Furthermore, once groups of participants that can be used to obtain estimates for nonparticipants have been identified, the groups may be so small that tests of whether the groups differ from each other lack statistical power. When, for example, researchers make the difference between those who are easy to contact and those who are difficult to contact large (and try to minimize variation within each group), they may be left with few hard-to-contact participants.

Methods based on either the continuum-of-resistance or classes models are essentially ad hoc ways to estimate the impact of nonparticipation on survey estimates of means and proportions. These methods have received continuing attention, but there have been few systematic attempts to evaluate either method using external data. In this study, we examine the usefulness of both approaches using data that include values for both participants and nonparticipants. Because our sample is from a list of court cases, we modify previous applications of these models slightly. For the continuum-of-resistance method, we distinguish the effort required to locate participants and the effort required to interview a located respondent. For the classes method, we differentiate hard-to-locate from easy-to-locate respondents. Because Stinchcombe and his colleagues (1981) offer the most developed discussion of classes-based methods, we draw on their work for an extended examination of this type of method and consider how response errors may affect conclusions about nonparticipation bias. Because both mothers and fathers from the court cases were interviewed, we have two separate, although not independent, instances in which to examine the usefulness of the models. 


\section{THE SAMPLE AND DATA}

The analysis uses three sources of data: the Court Record Database (CRD), the Parent Survey (PS), and documentation of field procedures from survey calling sheets (CS). The CRD records official information from court records for a sample of divorce cases with child support-eligible children entering the courts between 1984 and 1986 in twenty Wisconsin counties. The court records provide a unique opportunity for validating parents' self-reports about child support, because according to state law, court-ordered child support must be transferred between parents through the Clerk of Courts. A subsample of resident and nonresident parents from the same court cases in the CRD was selected for telephone interviews in the PS in $1987 .^{2}$ The PS obtained reports about the amount of child support owed and paid in 1986, and also asked for the amount of support that was not paid through the court as required. We subtract these direct payments from the PS self-reports in this analysis, so that the amounts recorded by the CRD and the PS are as comparable as possible (see Schaeffer in press). The CS provides information about all locating and interviewing calls to all telephone numbers and the result of each call. The CS includes the final disposition for each case, the number of calls made for each case, the number of different telephone numbers called, and the number of times each parent refused. This analysis examines the 1386 divorce cases in which the mother was the resident parent in most of 1986. The dependent variables in this analysis are the average amounts of child support owed and paid. ${ }^{3}$ (Appendix A presents the exact wording of the questions about child support.) We present separate analyses for resident mothers (who are owed and paid child support) and nonresident fathers (who owe and pay child support).

The combination of the CRD and PS allows us to examine whether participants and nonparticipants differ with respect to an external criterion, the CRD. The availability of the PS and CRD does introduce some complications, however. A comparison of the PS and CRD indicates that 
the PS includes substantial response error (e.g., Schaeffer, Seltzer, and Klawitter 1991; Schaeffer in press). To eliminate the effects of response error, an evaluation of these ad hoc methods could rely on the CRD, which provides a common standard to use in examining differences among groups of respondents. A common standard is particularly important because response errors may differ for mothers and fathers (e.g., Schaeffer, Seltzer, and Klawitter 1991). But investigators relying on ad hoc methods for examining nonparticipation bias typically have only self-reports available to them, and this fact suggests presenting the data that an investigator would normally have available, that is, the PS. To keep the presentation compact given these conflicting considerations, in most of the analyses we present results from either the CRD or the PS and comment on how the results differ for the other data source.

The two principal causes of nonparticipation in the PS were problems in locating parents sampled from the CRD and refusals. The processes contributing to each type of nonparticipation are heterogeneous and probably differ somewhat for resident mothers and nonresident fathers. In order to locate parents, we obtained information from the original court case and directory assistance, and from the Department of Revenue, the Department of Transportation, the Aid to Families with Dependent Children (AFDC) agency, and the Unemployment Compensation files. A mailing was sent to those who could not be reached by telephone. Attempts were made to persuade all who refused the interview, and to interview those who had moved from the state. (See Bartfeld [1991] for details of the field procedures.) These resources and procedures probably favored finding parents who remained in Wisconsin (probably more likely to be mothers), maintained their own residence (probably more likely to be fathers), and did not change names (more likely to be fathers). Because nonresident parents who do not pay the child support they owe are subject to criminal prosecution, it was probably more difficult to confirm the location of fathers in the sample (whose location may have been concealed by whoever answered the telephone), and some sampled fathers had a reason to refuse that 
did not apply to the sampled mothers. In a previous study of these data, Schaeffer et al. (1991) found that nonparticipants were less likely to have awards or to pay support than participants, and that the average awards and average amount paid were lower for persons who were not interviewed than for participants. It seems that measures related to child support may be correlated with parents' accessibility.

\section{RESULTS: THE CONTINUUM-OF-RESISTANCE METHOD}

In examining whether or not there is a continuum of resistance, researchers have used the total number of calls or contacts made for each sample member as an indicator of the effort required to interview the respondent and, hence, as an indicator of the respondent's resistance (Hawkins 1975; Fitzgerald and Fuller 1982; Dunkelberg and Day 1973; Traugott 1987; Thomsen and Siring 1983). However, depending on the study design, the total number of calls made to complete an interview may confound different types of calls. For some participants, a large proportion of calls may be used to contact the person; once contacted, the respondent may be easy to interview.

To take the study design into account, we examined two indicators of the total level of effort required to interview respondents, separately for resident mothers and nonresident fathers (data not shown): the total number of calls (both locating and contacting calls), and the number of calls to the last telephone number at which we tried to contact a parent (for respondents, this is the telephone number at which the interview was completed). The relationship between the conditional probability of being interviewed (given that the respondent was not interviewed on the prior call) and the level of effort may suggest which indicator better reflects the difficulty of obtaining an interview. For both resident mothers and nonresident fathers, the probability of being interviewed generally declines as the total number of calls or the number of calls to the last telephone number increases (data not shown), although the decline is not steady (see Lin [1990] for data on mothers). However, the number of calls 
at the last telephone number has a clearer interpretation as an indicator of the effort required to interview a located respondent, and a similar indicator could be devised for most study designs. If the factors affecting how easy it is to locate a parent differ from factors that affect how easy it is to contact or persuade a parent, combining the two types of calls would be inappropriate. Thus, if there is a regular relationship between survey variables and the level of effort required to obtain an interview, in this study design, such a relationship should be stronger when using the number of calls at the last telephone number.

Figure 1 and Figure 2 present the mean dollars of child support owed and paid by the number of calls to the telephone number at which the parent was interviewed, separately for resident mothers and nonresident fathers. This analysis could use either the CRD or the PS. But only the CRD allows nonparticipants to be included on the continuum of resistance and provides a criterion to use in evaluating apparent differences and, hence, the usefulness of the approach. And so we use the CRD and comment on differences between these and results obtained using the PS. ${ }^{4}$ The means for dollars of child support owed and paid are calculated from grouped data after ten calls because the number of cases receiving ten or more calls is small. (See Appendix B for frequency distributions.) Means for all nonparticipants and for refusers separately are entered at the far right of the continuum.

The first question in evaluating this approach is whether there appears to be a continuum of resistance among participants. Roughly speaking, mothers who required fewer calls at the last telephone number have somewhat lower amounts of child support owed and paid, and mothers who received more calls have higher amounts of support owed or paid. At intermediate numbers of calls, however, the pattern is irregular; the relationship is much flatter and more irregular for fathers. Results are similar using the PS (data not shown); overall, the contrast between those with few and those with many calls appears strongest for fathers using the PS and for mothers using the CRD. 
Figure 1 here 
Figure 2 here 
The second question is whether nonparticipants can be placed at the end of any continuum that appears. Two groups of nonrespondents are at the end of the continuum in the figures. One group includes all nonparticipants. ${ }^{5}$ Another group has refusers only. Dotted lines in the figures show that the means of child support owed and paid for refusers only are closer to the means for all nonrespondents than to the means for hard-to-locate respondents. For the group of all nonparticipants, the means of child support owed and paid are more similar to the means for respondents who need fewer calls than to the means for respondents who need more calls. This pattern appears for both mothers and fathers, and does not support the continuum-of-resistance model. But if the means for refusers only (29 percent of nonparticipating mothers and 31 percent of nonparticipating fathers) are examined, the model appears somewhat more plausible for mothers, although not for fathers.

If, following others who have examined whether there is a continuum of resistance, we calculate cumulative means by including all respondents interviewed by a given call (not shown), the mean changes very little after five to seven calls. This is because the number of respondents added after each contact is too small to greatly affect the cumulative mean, not because of the characteristics of the respondents who require more effort to interview.

In summary, the probability of completing an interview generally declines as our indicator of effort, the number of calls at the final telephone number, increases. When we examine the average amounts of support owed and paid, calculated directly for each group of respondents receiving a given number of calls, there appears to be some relationship with level of effort for mothers, but not for fathers. For mothers, the possible relationship receives some additional support if refusers are considered separately from other nonparticipants, but not otherwise. The results for mothers suggest that whether or not a continuum of resistance appears plausible may be sensitive to heterogeneity among nonparticipants, which is partially a function of study design and field procedures. The comparison between mothers and fathers also indicates that such a relationship cannot be taken for 
granted. The difference between the two groups may be a chance result or a function of the slightly lower participation rate of fathers, which may interact with fathers' different reasons for refusing participation.

\section{RESULTS: THE CLASSES METHOD}

Stinchcombe et al. (1981) concluded that, for their sample, nonparticipation bias was more likely to be caused by those who refused than by those who were not contacted. Thus, they estimated nonparticipation bias by assigning sample estimates of means calculated among respondents who had never refused to potential respondents among those who were never contacted. They assigned similar estimates based on respondents who temporarily refused to final refusers and potential refusers among those who were never contacted. To apply and extend this approach to the present study design requires a few modifications, most importantly to take into account that our principal field issue is locating not contacting respondents. ${ }^{6}$ To differentiate respondents who were easy to locate from those who were hard to locate, we examined the conditional probabilities of locating a parent (i.e., the probability of locating a parent on the second call given that she was not located on the first call) by the number of different telephone numbers that were called before the parent was ultimately located.

This probability declines as the number of different telephone numbers increases, but the relationship is somewhat different for mothers and fathers. For mothers, the probability declines from .87 at one telephone number to .80 at three telephone numbers, and then stays constant. For fathers, the probability is roughly constant (approximately .79) up to three telephone numbers and then drops off sharply (to approximately .63). ${ }^{7}$ In order to examine whether respondents for whom more telephone numbers were called before they were located differed from other respondents, we examined the relationship between this indicator and the means and standard deviations of child support awards 
and payments. Here we present results from the PS, because investigators would have to rely on such self-reports in making decisions about how to apply the classes model.

Figure 3 shows that for mothers, the mean amount of child support owed and paid reported in the PS declines, generally smoothly, with the number of different telephone numbers called: the mean amount of child support owed declines $\$ 1328$ from those for whom we called one telephone number to those for whom we tried five or more telephone numbers (from \$3876 to \$2548), and the mean child support paid declines $\$ 1281$ (from $\$ 3069$ to $\$ 1788$ ). A negative relationship with the number of different telephone numbers called also exists for the standard deviations of these two variables, suggesting that hard-to-locate mothers are more homogeneous than easy-to-locate mothers. However, as Figure 4 shows, these regular patterns do not appear for fathers. Although the mean amount of child support owed in the PS also declines $\$ 445$ from those for whom we called one telephone number to those for whom we called five or more telephone numbers (from $\$ 4018$ to $\$ 3573$ ), and the mean amount of child support paid declines \$271 (from \$3656 to \$3385), the relationship is flatter than that for mothers. In addition, fathers who required more effort to locate do not appear to become increasingly homogeneous on either variable. The results are very similar using the CRD (data not shown). ${ }^{8}$ Again, it appears plausible that the processes making parents difficult to locate or leading parents to refuse differ somewhat for mothers and fathers.

Examining the pattern of means by the number of telephone numbers called suggests that--at least for mothers--classifying respondents for whom up to three telephone numbers were called as easy-to-locate might be reasonable. For fathers, the pattern of means and standard deviations does not suggest a clear decision; but the decline in the probability of locating a respondent after three numbers were called suggests that the same criterion might be used for fathers. This threshold considers that one must attempt to maximize the difference between easy- and difficult-to-locate 
Figure 3 here 
Figure 4 here 
respondents without making the latter group too small for a useful comparison. ${ }^{9}$ But the ad hoc character of this decision is apparent and inevitable.

Table 1 presents the eight final case dispositions used in this application of the classes model for the 1386 mothers and fathers in the sample. We distinguish more types of nonparticipants than previous applications of this approach to aid in evaluating whether finer distinctions might be useful and to facilitate comparisons between our results and those obtained from other designs. Respondents for whom four or more telephone numbers were called and who were interviewed are classified as "interviewed, hard to locate." Respondents who gave a "soft" refusal, for example by saying "I am very busy right now," but who were interviewed in later callbacks are distinguished from those who gave a hard temporary refusal, for example by saying "I do not want to participate in the survey." 10 We also distinguish unlocated parents for whom our locating efforts found at least one telephone number and unlocated parents for whom none of the court records, directory assistance, or the state agency files we examined were able to supply information leading to a telephone number. There is a small residual "other" category that we omit in later analyses.

The results in Table 1 suggest that the average level of effort absorbed by a case varies by final outcome. For both mothers and fathers, the average number of calls required to complete an interview at the final telephone number is roughly similar for those who are easy and difficult to locate. The average number of telephone calls to those who ever refuse is approximately twice that of the mean for those who never refused. The mean number of telephone numbers that were tried before the respondent was located is similar for all groups except those who were difficult to locate--a group that is distinct from those who were easy to locate by design.

In order to evaluate the classes model, we first examine, in Table 2, whether the CRD indicates that there may be systematic differences among the groups of participants and nonparticipants when response errors are ignored. The ordering of the categories is suggested by 
TABLE 1

Indicators of Level of Effort, by Final Disposition

\begin{tabular}{|c|c|c|c|}
\hline Final Disposition & $\begin{array}{l}\text { Number of } \\
\text { Calls at Final } \\
\text { Telephone Number }\end{array}$ & $\begin{array}{l}\text { Number of } \\
\text { Telephone Numbers }\end{array}$ & $\mathrm{N}$ \\
\hline \multicolumn{4}{|l|}{ Divorced resident mothers } \\
\hline Final refusal & $\begin{array}{c}9.52 \\
(9.42)\end{array}$ & $\begin{array}{l}1.46 \\
(.88)\end{array}$ & 122 \\
\hline Hard temporary refusal & $\begin{array}{l}11.35 \\
(11.28)\end{array}$ & $\begin{array}{c}1.54 \\
(1.12)\end{array}$ & 37 \\
\hline Soft temporary refusal & $\begin{array}{l}11.14 \\
(8.75)\end{array}$ & $\begin{array}{l}1.49 \\
(.74)\end{array}$ & 35 \\
\hline Interviewed, easy to locate & $\begin{array}{c}4.94 \\
(4.98)\end{array}$ & $\begin{array}{l}1.38 \\
(.60)\end{array}$ & 848 \\
\hline Interviewed, hard to locate & $\begin{array}{c}4.62 \\
(3.74)\end{array}$ & $\begin{array}{c}4.92 \\
(1.61)\end{array}$ & 39 \\
\hline Unlocated, at least one number found & $\begin{array}{c}3.69 \\
(4.86)\end{array}$ & $\begin{array}{c}1.70 \\
(1.04)\end{array}$ & 187 \\
\hline Unlocated, no numbers found & -- & -- & 107 \\
\hline Other & $\begin{array}{c}10.64 \\
(11.38)\end{array}$ & $\begin{array}{l}1.45 \\
(.52)\end{array}$ & 11 \\
\hline Total sample & $\begin{array}{c}5.59 \\
(6.30)\end{array}$ & $\begin{array}{l}1.55 \\
(.99)\end{array}$ & 1386 \\
\hline $\mathrm{N}$ & 1279 & 1279 & \\
\hline \multicolumn{4}{|l|}{ Divorced nonresident fathers } \\
\hline Final refusal & $\begin{array}{c}13.89 \\
(15.41)\end{array}$ & $\begin{array}{l}1.66 \\
(.81)\end{array}$ & 179 \\
\hline Hard temporary refusal & $\begin{array}{l}13.96 \\
(11.07)\end{array}$ & $\begin{array}{l}1.62 \\
(.98)\end{array}$ & 45 \\
\hline Soft temporary refusal & $\begin{array}{l}12.67 \\
(13.85)\end{array}$ & $\begin{array}{c}1.91 \\
(1.28)\end{array}$ & 46 \\
\hline Interviewed, easy to locate & $\begin{array}{c}6.84 \\
(7.36)\end{array}$ & $\begin{array}{l}1.54 \\
(.69)\end{array}$ & 651 \\
\hline Interviewed, hard to locate & $\begin{array}{c}5.77 \\
(6.73)\end{array}$ & $\begin{array}{c}4.94 \\
(1.21)\end{array}$ & 35 \\
\hline Unlocated, at least one number found & $\begin{array}{c}5.50 \\
(9.68)\end{array}$ & $\begin{array}{c}1.86 \\
(1.21)\end{array}$ & 274 \\
\hline Unlocated, no numbers found & -- & -- & 133 \\
\hline Other & $\begin{array}{c}9.26 \\
(13.53)\end{array}$ & $\begin{array}{l}1.57 \\
(.59)\end{array}$ & 23 \\
\hline Total sample & $\begin{array}{c}8.04 \\
(10.35)\end{array}$ & $\begin{array}{c}1.74 \\
(1.05)\end{array}$ & 1386 \\
\hline $\mathrm{N}$ & 1253 & 1253 & \\
\hline
\end{tabular}

Note: Cell entries are means and standard deviations (in parentheses) for the indicators of level of effort. "Other" category includes cases that were not completed because the respondent broke off the interview, did not speak English, was reported overseas, or was located but not interviewed before the field period ended. Cases for which four or more telephone numbers were obtained before the respondent was located are classified as "hard to locate." 
TABLE 2

Child Support Variables from the Court Record Data, by Final Disposition

\begin{tabular}{|c|c|c|c|c|}
\hline Final Disposition & $\begin{array}{l}\text { Mean Dollars } \\
\text { of Child } \\
\text { Support Owed }\end{array}$ & $\begin{array}{c}\text { Mean } \\
\text { Dollars of Child } \\
\text { Support Owed (Log) }\end{array}$ & $\begin{array}{l}\text { Mean Dollars } \\
\text { of Child } \\
\text { Support Paid }\end{array}$ & \begin{tabular}{l}
\multicolumn{1}{c}{ Mean } \\
Dollars of Child \\
Support Paid (Log)
\end{tabular} \\
\hline \multicolumn{5}{|l|}{ Divorced resident mothers } \\
\hline Final refusal & $\begin{array}{l}4811 \\
(7445)\end{array}$ & $\begin{array}{l}7.36 \\
(2.42)\end{array}$ & $\begin{array}{l}3355 \\
(6691)\end{array}$ & $\begin{array}{l}5.26 \\
(3.87)\end{array}$ \\
\hline Hard temporary refusal & $\begin{array}{c}4614 \\
(4829)\end{array}$ & $\begin{array}{c}7.34 \\
(2.76)\end{array}$ & $\begin{array}{c}3779 \\
(5389)\end{array}$ & $\begin{array}{c}5.95 \\
(3.76)\end{array}$ \\
\hline Soft temporary refusal & $\begin{array}{c}3786 \\
(3042)\end{array}$ & $\begin{array}{l}7.13 \\
(2.76)\end{array}$ & $\begin{array}{c}2997 \\
(3113)\end{array}$ & $\begin{array}{c}5.36 \\
(3.99)\end{array}$ \\
\hline Interviewed, easy to locate & $\begin{array}{c}3362 \\
(3605)\end{array}$ & $\begin{array}{c}7.25 \\
(2.28)\end{array}$ & $\begin{array}{c}2479 \\
(4015)\end{array}$ & $\begin{array}{c}5.22 \\
(3.72)\end{array}$ \\
\hline Interviewed, hard to locate & $\begin{array}{l}2598 \\
(2176)\end{array}$ & $\begin{array}{c}6.68 \\
(2.76)\end{array}$ & $\begin{array}{c}1649 \\
(2377)\end{array}$ & $\begin{array}{c}4.15 \\
(3.84)\end{array}$ \\
\hline $\begin{array}{l}\text { Unlocated, at least one } \\
\text { number found }\end{array}$ & $\begin{array}{l}2425 \\
(2614)\end{array}$ & $\begin{array}{c}6.33 \\
(3.03)\end{array}$ & $\begin{array}{c}1386 \\
(2289)\end{array}$ & $\begin{array}{c}3.65 \\
(3.81)\end{array}$ \\
\hline $\begin{array}{l}\text { Unlocated, no numbers } \\
\text { found }\end{array}$ & $\begin{array}{c}2843 \\
(3544)\end{array}$ & $\begin{array}{c}6.33 \\
(3.08)\end{array}$ & $\begin{array}{c}1897 \\
(3385)\end{array}$ & $\begin{array}{c}3.97 \\
(3.93)\end{array}$ \\
\hline Total sample & $\begin{array}{c}3348 \\
(4026)\end{array}$ & $\begin{array}{c}7.05 \\
(2.53)\end{array}$ & $\begin{array}{c}2387 \\
(4117)\end{array}$ & $\begin{array}{c}4.91 \\
(3.82)\end{array}$ \\
\hline $\mathrm{N}$ & 1353 & 1353 & 1375 & 1375 \\
\hline \multicolumn{5}{|l|}{ Divorced nonresident fathers } \\
\hline Final refusal & $\begin{array}{c}3451 \\
(3007)\end{array}$ & $\begin{array}{l}7.34 \\
(2.23)\end{array}$ & $\begin{array}{l}2520 \\
(3171)\end{array}$ & $\begin{array}{l}5.00 \\
(3.92)\end{array}$ \\
\hline Hard temporary refusal & $\begin{array}{l}3888 \\
(5029)\end{array}$ & $\begin{array}{l}7.28 \\
(2.45)\end{array}$ & $\begin{array}{c}3435 \\
(5525)\end{array}$ & $\begin{array}{c}5.60 \\
(3.87)\end{array}$ \\
\hline Soft temporary refusal & $\begin{array}{l}2843 \\
(2294)\end{array}$ & $\begin{array}{c}7.06 \\
(2.38)\end{array}$ & $\begin{array}{c}2247 \\
(2831)\end{array}$ & $\begin{array}{c}4.48 \\
(4.05)\end{array}$ \\
\hline Interviewed, easy to locate & $\begin{array}{l}3695 \\
(4561)\end{array}$ & $\begin{array}{l}7.36 \\
(2.21)\end{array}$ & $\begin{array}{c}2807 \\
(4847)\end{array}$ & $\begin{array}{c}5.48 \\
(3.67)\end{array}$ \\
\hline Interviewed, hard to locate & $\begin{array}{c}4043 \\
(4955)\end{array}$ & $\begin{array}{c}7.59 \\
(2.03)\end{array}$ & $\begin{array}{c}2342 \\
(3153)\end{array}$ & $\begin{array}{c}5.52 \\
(3.62)\end{array}$ \\
\hline $\begin{array}{l}\text { Unlocated, at least one } \\
\text { number found }\end{array}$ & $\begin{array}{l}2559 \\
(2945)\end{array}$ & $\begin{array}{c}6.42 \\
(2.96)\end{array}$ & $\begin{array}{l}1560 \\
(2807)\end{array}$ & $\begin{array}{c}4.11 \\
(3.77)\end{array}$ \\
\hline $\begin{array}{l}\text { Unlocated, no numbers } \\
\text { found }\end{array}$ & $\begin{array}{c}2889 \\
(3983)\end{array}$ & $\begin{array}{c}6.10 \\
(3.29)\end{array}$ & $\begin{array}{l}1500 \\
(3281)\end{array}$ & $\begin{array}{c}3.29 \\
(3.80)\end{array}$ \\
\hline Total sample & $\begin{array}{l}3345 \\
(4030)\end{array}$ & $\begin{array}{c}7.04 \\
(2.55)\end{array}$ & $\begin{array}{c}2381 \\
(4121)\end{array}$ & $\begin{array}{c}4.90 \\
(3.82)\end{array}$ \\
\hline $\mathrm{N}$ & 1342 & 1342 & 1363 & 1363 \\
\hline
\end{tabular}

Note: Cell entries are means and standard deviations (in parentheses) of the column variables. Cases for which four or more telephone numbers were obtained before the respondent was located are classified as "hard to locate." The reference period for all variables is 1986. Total sample excludes cases with the final disposition "other." 
previous research which finds that refusers may have higher incomes than survey participants (Duncan and Mathiowetz 1985, p. 42) and previous analyses of these data (Schaeffer et al. 1991). Because the distributions of these variables are highly positively skewed, we also present means for natural logs of the amount of support owed and paid. For mothers, there is a rough ordering of the mean amounts of child support owed and paid. From lowest to highest this order is: those who were unlocated or who were interviewed but difficult to locate, those who were interviewed and easy to locate, and those who gave temporary or final refusals. This ordering is not present for fathers, however, except that the means for those who were not located are lower than those for the other groups. The group of parents who were not located and for whom no telephone number to use in locating could be found is more heterogeneous than the group of unlocated parents for whom at least one telephone number was found, on both variables for both mothers and fathers. Table 3 presents comparable statistics for the selfreports in the PS. Mothers' self-reports show the pattern observed in the CRD. For fathers, it appears that only the hard temporary refusers might be a distinct group. Fathers who were easy and difficult to locate appear quite similar to each other, as the results in Figure 4 suggested would be the case. ${ }^{11}$

Overall, Table 2 suggests that in this sample, those who were not located are probably different from participants and that refusers may be in some cases. But it is less clear whether the different groups of respondents are different from each other. Table 3 suggests that when, as for mothers, the level of effort and refusal status appear somewhat successful in identifying different classes of participants (using the CRD as a criterion), these differences may also appear in the sample. Comparing Table 2 and Table 3, it appears that the average amounts of support owed and paid are overstated by the PS sample as a whole. In part this is due to the substantial number of unlocated respondents with lower-than-average amounts of support owed and paid. In addition, on average, both mothers and fathers appear to overreport the amount of child support owed and paid 
TABLE 3

Child Support Variables from the Parent Survey, by Final Disposition

\begin{tabular}{|c|c|c|c|c|}
\hline Final Disposition & $\begin{array}{l}\text { Mean Dollars } \\
\text { of Child } \\
\text { Support Owed }\end{array}$ & $\begin{array}{l}\text { Mean } \\
\text { Dollars of Child } \\
\text { Support Owed (Log) }\end{array}$ & $\begin{array}{l}\text { Mean Dollars } \\
\text { of Child } \\
\text { Support Paid }\end{array}$ & $\begin{array}{l}\text { Mean } \\
\text { Dollars of Child } \\
\text { Support Paid (Log) }\end{array}$ \\
\hline \multicolumn{5}{|c|}{ Interviewed divorced resident mothers } \\
\hline Hard temporary refusal & $\begin{array}{c}4829 \\
(4680)\end{array}$ & $\begin{array}{c}7.24 \\
(3.02)\end{array}$ & $\begin{array}{c}3809 \\
(5094)\end{array}$ & $\begin{array}{c}5.58 \\
(3.97)\end{array}$ \\
\hline Soft temporary refusal & $\begin{array}{c}4062 \\
(3631)\end{array}$ & $\begin{array}{c}7.15 \\
(2.84)\end{array}$ & $\begin{array}{c}3511 \\
(4046)\end{array}$ & $\begin{array}{c}5.64 \\
(3.95)\end{array}$ \\
\hline Interviewed, easy to locate & $\begin{array}{c}3687 \\
(3919)\end{array}$ & $\begin{array}{c}7.11 \\
(2.73)\end{array}$ & $\begin{array}{c}2854 \\
(3979)\end{array}$ & $\begin{array}{c}5.81 \\
(3.55)\end{array}$ \\
\hline Interviewed, hard to locate & $\begin{array}{c}2937 \\
(2254)\end{array}$ & $\begin{array}{c}6.54 \\
(3.20)\end{array}$ & $\begin{array}{c}2374 \\
(2518)\end{array}$ & $\begin{array}{c}5.23 \\
(3.85)\end{array}$ \\
\hline Total sample & $\begin{array}{c}3714 \\
(3891)\end{array}$ & $\begin{array}{c}7.09 \\
(2.77)\end{array}$ & $\begin{array}{c}2897 \\
(3988)\end{array}$ & $\begin{array}{c}5.77 \\
(3.59)\end{array}$ \\
\hline $\mathrm{N}$ & 901 & 901 & 841 & 841 \\
\hline \multicolumn{5}{|c|}{ Interviewed divorced nonresident fathers } \\
\hline Hard temporary refusal & $\begin{array}{c}5093 \\
(8813)\end{array}$ & $\begin{array}{c}7.61 \\
(2.28)\end{array}$ & $\begin{array}{c}5167 \\
(9274)\end{array}$ & $\begin{array}{c}7.36 \\
(2.69)\end{array}$ \\
\hline Soft temporary refusal & $\begin{array}{c}3528 \\
(3002)\end{array}$ & $\begin{array}{c}6.51 \\
(3.40)\end{array}$ & $\begin{array}{c}3009 \\
(3053)\end{array}$ & $\begin{array}{c}5.63 \\
(3.83)\end{array}$ \\
\hline Interviewed, easy to locate & $\begin{array}{c}3969 \\
(4645)\end{array}$ & $\begin{array}{c}7.05 \\
(2.89)\end{array}$ & $\begin{array}{c}3578 \\
(4715)\end{array}$ & $\begin{array}{c}6.48 \\
(3.31)\end{array}$ \\
\hline Interviewed, hard to locate & $\begin{array}{c}3865 \\
(4137)\end{array}$ & $\begin{array}{c}7.01 \\
(2.97)\end{array}$ & $\begin{array}{c}3533 \\
(4311)\end{array}$ & $\begin{array}{c}6.44 \\
(3.40)\end{array}$ \\
\hline Total sample & $\begin{array}{c}4000 \\
(4861)\end{array}$ & $\begin{array}{c}7.05 \\
(2.90)\end{array}$ & $\begin{array}{c}3622 \\
(4953)\end{array}$ & $\begin{array}{c}6.47 \\
(3.32)\end{array}$ \\
\hline $\mathrm{N}$ & 755 & 755 & 721 & 721 \\
\hline
\end{tabular}

Note: Cell entries are means and standard deviations (in parentheses) of the column variables. Cases for which four or more telephone numbers were obtained before the respondent was located are classified as "hard to locate." Dollar amounts that parents reported they exchanged directly are excluded. The reference period for all variables is 1986 . Total sample excludes cases with the final disposition "other." 
(see Schaeffer et al. 1991). The adjustment for nonparticipation bias that is the goal of the method being examined here cannot correct for these response errors, and there is no obvious way to adapt the model to take these errors into account.

Although those who have used variants of the classes model have not tested whether the groups they distinguish differ significantly from each other, this is a useful step in evaluating the classes model. We use the Bonferroni method of multiple comparisons for this test because several comparisons are made, and so a simultaneous estimation of a family confidence interval is necessary (Neter, Wasserman, and Kutner 1989, pp. 163-165). Also, not all pairwise comparisons are interesting to us. We are particularly interested in nine comparisons (see Table 4). This method of multiple comparisons increases the difficulty of rejecting the null hypothesis, even when the observed difference between two group means is large because it uses a pooled variance and because the number of cases in some of the groups is small. However, these conditions will always be true when making comparisons required by the model of classes. Although we could adjust the classifications to increase the number of hard-to-locate respondents, this could lose what distinctiveness the category has. In testing whether the difference between two group means may be significant, we use the 10 percent level of significance, because of the small size of some of the groups and the ad hoc character of this method.

The results in Table 4 address both whether the CRD suggests the groups "actually" differ (Panel A) and whether or not any differences appear when response error is added to other sources of error (Panel B). The model of classes assumes that some of these comparisons will fail and others succeed, but support for the model is mixed. First, the CRD data suggest that the two groups of nonparticipating mothers--unlocated and refusing mothers--differ from each other. Although the results are less consistent for fathers, when logs of the amounts of support owed and paid are tested (not shown), the groups differ significantly for both variables $(\mathrm{p}<.01)$. It also appears that none of 
TABLE 4

T-values for Comparisons of Group Means for the Court Record Data and Parent Survey Variables

\begin{tabular}{|c|c|c|c|c|}
\hline \multirow[b]{2}{*}{ Comparisons of Group Means } & \multicolumn{2}{|c|}{ Mothers } & \multicolumn{2}{|c|}{ Fathers } \\
\hline & $\begin{array}{l}\text { Mean Dollars } \\
\text { of Child } \\
\text { Support Owed }\end{array}$ & $\begin{array}{l}\text { Mean Dollars } \\
\text { of Child } \\
\text { Support Paid }\end{array}$ & $\begin{array}{l}\text { Mean Dollars } \\
\text { of Child } \\
\text { Support Owed }\end{array}$ & $\begin{array}{l}\text { Mean Dollars } \\
\text { of Child } \\
\text { Support Paid }\end{array}$ \\
\hline \multicolumn{5}{|l|}{ A. Court Record Data } \\
\hline Final refusal $v s$. unlocated parents & $4.99^{* * *}$ & $3.85^{* * *}$ & 1.96 & $2.65^{*}$ \\
\hline $\begin{array}{l}\text { Hard temporary refusal } v s . \text { soft } \\
\text { temporary refusal }\end{array}$ & .86 & .81 & 1.23 & 1.39 \\
\hline Final refusal $v s$. temporary refusal & 1.02 & -.05 & .17 & -.61 \\
\hline $\begin{array}{l}\text { Unlocated, no number found } v s \text {. } \\
\text { unlocated, at least one number } \\
\text { found }\end{array}$ & .85 & 1.03 & .77 & -.14 \\
\hline $\begin{array}{l}\text { Unlocated parents } v s \text {. interviewed, } \\
\text { hard to locate }\end{array}$ & .05 & -.01 & -1.86 & -1.12 \\
\hline $\begin{array}{l}\text { Interviewed, easy to locate } v s \\
\text { unlocated parents }\end{array}$ & $2.60^{*}$ & $2.94^{* *}$ & $3.64^{* * *}$ & $4.75^{* * *}$ \\
\hline $\begin{array}{l}\text { Interviewed, easy to locate } v s \text {. } \\
\text { interviewed, hard to locate }\end{array}$ & 1.16 & 1.24 & -.50 & .65 \\
\hline $\begin{array}{l}\text { Final refusal } v s . \text { interviewed, } \\
\text { easy to locate }\end{array}$ & $3.75^{* * *}$ & 2.21 & -.72 & -.83 \\
\hline $\begin{array}{l}\text { Temporary refusal } v s . \text { interviewed, } \\
\text { easy to locate }\end{array}$ & 1.68 & 1.81 & -.73 & .07 \\
\hline \multicolumn{5}{|l|}{ B. Parent Survey } \\
\hline $\begin{array}{l}\text { Hard temporary refusal } v s . \text { soft } \\
\text { temporary refusal }\end{array}$ & .74 & .30 & 1.48 & 1.95 \\
\hline $\begin{array}{l}\text { Interviewed, easy to locate } v s \text {. } \\
\text { interviewed, hard to locate }\end{array}$ & .91 & .68 & .12 & .05 \\
\hline $\begin{array}{l}\text { Temporary refusal } v s \text {. interviewed, } \\
\text { easy to locate }\end{array}$ & 1.80 & 1.54 & 1.80 & .87 \\
\hline
\end{tabular}

$$
{ }^{*} \mathrm{p}<.10^{* * *} \mathrm{p}<.0{ }^{* * * *} \mathrm{p}<.01
$$

Note: Divorced mothers who have physical custody and their corresponding divorcing spouses are included in this sample. The reference period for all variables is 1986. The CRD analysis includes 1375 cases (cases with final disposition of "other" are excluded [N=11]); the PS analysis includes 964 divorced resident mothers and 786 divorced nonresident fathers. Cell entries are $t$ statistics based on the Bonferroni method of multiple comparisons $(t$ statistics $=t(1-$ $\alpha / 2 * \mathrm{~g} ; \mathrm{n}$ ), where $1-\alpha$ is the family confidence coefficient, $\mathrm{g}$ is the number of group comparisons, and $\mathrm{n}$ is the number of cases). For the joint estimation of nine comparisons (CRD), the 90th percentile of the $t$ distribution (two-sided) with 1375 degrees of freedom is $t(1-.10 / 2 * 9,1375)=2.54$, the 95 th percentile is $t(1-.05 / 2 * 9,1375)=2.77$, and the 99th percentile is $t(1-.01 / 2 * 9,1375)=3.26$. For the joint estimation of three comparisons (PS) among mothers, the 90th percentile of the $t$ distribution (two-sided) with 964 degrees of freedom is $t(1-.10 / 2 * 3,964)=2.13$, the 95 th percentile is $t(1-.05 / 2 * 3,964)=2.39$, and the 99 th percentile is $t(1-.01 / 2 * 3,964)=2.93$. For the joint estimation of three comparisons (PS) among fathers, the 90th percentile of the $t$ distribution (two-sided) with 964 degrees of freedom is $t(1-.10 / 2 * 9,786)$ $=2.13$, the 95th percentile is $t(1-.05 / 2 * 3,786)=2.39$, and the 99th percentile is $t(1-.01 / 2 * 3,786)=2.93$. 
the groups of temporary or final refusers differ significantly from each other for either mothers or fathers. Similarly, for both mothers and fathers, the two groups of unlocated parents are similar to each other and to the hard-to-locate respondents. These latter two null effects are compatible with the model. But the distinctions the model predicts do not appear. Although mothers and fathers who are easy to locate differ from those who are not located, at least in support paid, they do not differ from those who are difficult to locate. Similarly, although mothers who ultimately refuse differ from those who are easy to locate for support owed in the results in Table 4, the comparison fails when logs are analyzed, and the latter group does not differ from the temporary refusers; neither difference is significant for mothers for support paid or for either variable for fathers. ${ }^{12}$ Moreover, the results in Table 4 indicate that none of these differences are significant in the PS; the overreporting by almost all groups of respondents appears to reduce even the differences between them that appear in the CRD.

These results make it seem plausible that, at least in this case, there are different types of nonparticipants, who probably differ from participants, so that something like the classes model might be applicable here. Although the patterns of means for mothers and fathers in Table 2 and Table 3 appear rather different, the pattern of significant results is very similar for both groups. The results are less promising, however, about the grounds for using groups of participants to estimate values for nonparticipants. Although the results in Table 4 do not justify treating those who were difficult to locate or who were temporary refusers as different from those who were easy to locate and interview, further examination of the classes model requires that we proceed as though at least some of these differences were significant. 


\section{CORRECTING SAMPLE ESTIMATES OF MEANS FOR NONPARTICIPATION BIAS}

To use groups of participants to estimate the characteristics of nonparticipants, Stinchcombe et al. (1981) assumed that people who were never contacted would, if contacted, participate and refuse in the proportions observed among those who were contacted. Thus, people who are not contacted can be divided into two groups, potential respondents and potential refusers. Stinchcombe et al. then assigned survey estimates based on respondents to the potential respondent group, and assigned survey estimates based on temporary refusers to the group of potential refusers and final refusers. This procedure allows ad hoc estimates of the population mean and nonparticipation bias to be estimated. Although there are several ways that this general approach could be extended to the current study design, our first estimates are essentially similar to those of Stinchcombe et al., except that we preserve the distinction between soft and hard temporary refusals. We then offer a slight modification. The calculations for mothers and fathers are presented in Appendix C.

Table 5 presents the estimates and related means for comparisons using the CRD and the PS. Using the CRD has two advantages. First, it provides an estimate of the population mean to use in estimating "true" nonparticipation bias and hence evaluating whether the method's estimate of nonparticipation bias is accurate. Second, it permits us to evaluate whether this ad hoc method of adjusting for nonparticipation is accurate when there is no response error. ${ }^{13}$ Comparing the CRD mean for the achieved sample (those actually interviewed) (row 1) with the CRD mean for the total sample (row 2), we can estimate the actual bias in the mean of the achieved sample (row 1 - row 2). For both mothers and fathers, the mean for the achieved sample is greater than that for the total sample, because a substantial proportion of the sample who were not located have, on average, lower values than the sample as a whole. However, using the classes-based method with the CRD data (row 3), one would conclude that the achieved sample underestimates the population mean (row 1 - row 3 ). Similarly, for the PS, the mean for the achieved sample is consistently larger than the actual mean 
TABLE 5

Estimates of Total Sample Means and Nonresponse Bias Using the Court Record Data and Parent Survey

\begin{tabular}{|c|c|c|c|c|}
\hline \multirow[b]{2}{*}{ Estimates } & \multicolumn{2}{|c|}{ Mothers } & \multicolumn{2}{|c|}{ Fathers } \\
\hline & $\begin{array}{l}\text { Mean Dollars } \\
\text { of Child } \\
\text { Support Owed }\end{array}$ & $\begin{array}{l}\text { Mean Dollars } \\
\text { of Child } \\
\text { Support Paid }\end{array}$ & $\begin{array}{l}\text { Mean Dollars } \\
\text { of Child } \\
\text { Support Owed }\end{array}$ & $\begin{array}{l}\text { Mean Dollars } \\
\text { of Child } \\
\text { Support Paid }\end{array}$ \\
\hline \multicolumn{5}{|l|}{ A. $\underline{\text { Court Record Data }}$} \\
\hline Mean for achieved sample (1) & 3393 & 2514 & 3672 & 2790 \\
\hline Mean for total sample (2) & 3348 & 2387 & 3345 & 2381 \\
\hline Estimated mean for total sample (3) & 3562 & 2678 & 3688 & 2875 \\
\hline Bias in achieved sample (1-2) & 45 & 127 & 327 & 409 \\
\hline Estimated bias in achieved sample (1-? & -3) -169 & -164 & -16 & -85 \\
\hline \multicolumn{5}{|l|}{ B. Parent Survey } \\
\hline Mean for achieved sample (4) & 3714 & 2897 & 4000 & 3622 \\
\hline Estimated mean for total sample (5) & 3873 & 3030 & 4159 & 3854 \\
\hline Bias in achieved sample (4-2) & 366 & 510 & 655 & 1241 \\
\hline Estimated bias in achieved sample (4-5 & $-5)-159$ & -133 & -159 & -232 \\
\hline
\end{tabular}

Note: Divorced mothers who have physical custody and their corresponding divorcing spouses are included in this sample. The reference period for all variables is 1986. The CRD analysis is based on 1386 cases; the PS analysis is based on 964 divorced resident mothers and 786 divorced nonresident fathers. The analysis excludes cases with final disposition of "other." 
from the CRD (row 4 - row 2). The method, however, leads to the conclusion that the mean for the total sample is underestimated by the achieved sample (row 4 - row 5). Furthermore, the method suggests that the absolute size of the bias is smaller for fathers than for mothers (using the CRD) or roughly similar for the two groups (using the PS), when in fact the bias is substantially greater for fathers.

The means in Table 3 suggest that the estimates might be improved--at least for mothers--by assuming that all potential respondents (.17 of the total sample of mothers and .22 of the total sample of fathers) would be like those who were hard to locate, and this is an adjustment that an investigator might reasonably make a priori for this study. (See Appendix $\mathrm{C}$ for the calculations.) The results in Table 6 show that the modified method improves most of the estimates of nonparticipation bias, but even the direction of the estimated bias is now correct for one variable using the CRD. Although it might be possible to further adjust the method to obtain better estimates of nonparticipation bias, such adjustments would require using knowledge of the CRD, knowledge that would not be available in most realistic situations.

\section{DISCUSSION}

Applying Stinchcombe et al.'s method leads us to conclude that the mean for the total sample is underestimated by the achieved sample, when the mean for the achieved sample is actually greater than that for the total sample. In the case examined by Stinchcombe et al., those who were difficult to contact appeared similar to those who were easy to contact, and they concluded that nonparticipation bias was most likely to result from refusals. Thus, their method imputes the mean for all those who

were interviewed to all potential respondents. A comparable conclusion--that the mean for those who were interviewed can be imputed to those who were not located--does not appear justifiable in our case. The large majority of our nonparticipants were not located (see Table 1). The 
TABLE 6

\section{Improved Estimates of Total Sample Means and Nonresponse Bias Using the Court Record Data and Parent Survey}

\begin{tabular}{|c|c|c|c|c|}
\hline & \multicolumn{2}{|c|}{ Mothers } & \multicolumn{2}{|c|}{ Fathers } \\
\hline & $\begin{array}{l}\text { Mean Dollars } \\
\text { of Child } \\
\text { Support Owed }\end{array}$ & $\begin{array}{l}\text { Mean Dollars } \\
\text { of Child } \\
\text { Support Paid }\end{array}$ & $\begin{array}{l}\text { Mean Dollars } \\
\text { of Child } \\
\text { Support Owed }\end{array}$ & $\begin{array}{l}\text { Mean Dollars } \\
\text { of Child } \\
\text { Support Paid }\end{array}$ \\
\hline \multicolumn{5}{|l|}{ A. $\underline{\text { Court Record Data }}$} \\
\hline Mean for achieved sample (1) & 3393 & 2514 & 3672 & 2790 \\
\hline Mean for total sample (2) & 3348 & 2387 & 3345 & 2381 \\
\hline Estimated mean for total sample (3) & 3439 & 2546 & 3761 & 2777 \\
\hline Bias in achieved sample (1-2) & 45 & 127 & 327 & 409 \\
\hline Estimated bias in achieved sample (1-3) & -46 & -32 & -89 & 13 \\
\hline \multicolumn{5}{|l|}{ B. Parent Survey } \\
\hline Mean for achieved sample (4) & 3714 & 2897 & 4000 & 3622 \\
\hline Estimated mean for total sample (5) & 3753 & 2953 & 4137 & 3845 \\
\hline Bias in achieved sample (4-2) & 366 & 510 & 655 & 1241 \\
\hline Estimated bias in achieved sample (4-5) & -39 & -56 & -137 & -223 \\
\hline
\end{tabular}

Note: Divorced mothers who have physical custody and their corresponding divorcing spouses are included in this sample. The reference period for all variables is 1986. The CRD analysis is based on 1386 cases; the PS analysis includes 964 divorced resident mothers and 786 divorced nonresident fathers. The analysis excludes cases with final disposition of "other." 
mean amounts of child support owed and paid in the sample were lowest for unlocated parents (see Table 2), in part because the proportion of parents owing or paying no child support is highest among unlocated parents. ${ }^{14}$ Thus, when the CRD mean for participants is assigned to unlocated parents, the resulting estimated mean for the total sample is not only greater than the mean for the achieved sample, but also much greater than the "true" mean. When the PS is used, the estimate of nonparticipation bias is even worse because, on average, participants overestimate child support owed and paid.

To attempt to improve estimates of nonparticipation bias for these data, we imputed the mean amounts of child support owed and paid for hard-to-locate respondents to all potential respondents. As Table 6 showed, this adjustment decreases the absolute size of the estimated bias for mothers although the estimated direction is still wrong. However, this adjustment provides no improvement for fathers. The difference between mothers and fathers occurs because hard-to-locate mothers are better "proxies" for unlocated mothers than hard-to-locate fathers are for unlocated fathers. The mean amounts of child support owed and paid for unlocated mothers are only slightly lower than those for hard-to-locate participating mothers (for owed, \$2577 vs. \$2598; for paid, \$1572 vs. \$1649), and the proportions of unlocated mothers with no child support owed or paid are close to those for hard-to-locate participating mothers (for owed, 17 percent vs. 12.8 percent; for paid, 49.7 percent vs. 43.6 percent). However, the mean amounts of child support owed and paid for unlocated fathers are much lower than those for hard-to-locate participating fathers (for owed, \$2667 vs. \$4043; for paid, \$1540 vs. \$2342), and the proportions of unlocated fathers with no child support owed or paid are much higher than those for hard-to-locate participating fathers (for owed, 17.7 percent vs. 5.7 percent; for paid, 48.5 percent vs. 28.6 percent).

Stinchcombe et al. (1981, p. 373, 375) note that at the least their method might make investigators cautious about ignoring nonparticipation bias. In the present case, however, the estimates 
of bias might make investigators overly sanguine--when the method is applied to data without response error for fathers, it suggests that the absolute value of nonparticipation bias is 0.4 percent to 4 percent of the mean, although the actual bias is 10 percent to 17 percent of the mean. Furthermore, the method leads to incorrect conclusions about the direction of bias and the relative size of bias for mothers and fathers. This failure occurs even though there appear to be some significant differences between participants and nonparticipants and, at least for mothers, some differences suggested by the model appear in the sample (even though they are not always significant).

The motivation to search for an easy, ad hoc method to adjust sample means for nonparticipation is easy to appreciate. These analyses suggest, however, that neither the continuum-of-resistance model nor the classes model provides a dependable answer to the question of how nonparticipation might bias estimates of means from a given sample. Given the complex processes determining survey participation, this may hardly seem surprising. Furthermore, the presentation clarifies that these methods really are ad hoc: they require a large number of small decisions--such as what to use as an indicator of the level of effort, how to distinguish easy-to-locate from hard-to-locate respondents, or what classes to use--that must be made without a great deal of guidance from either theory or data but which may greatly affect the resulting estimates of nonparticipation bias. The straightforward projections of the characteristics of nonparticipants suggested by the continuum of resistance cannot be assumed to be routinely justified, and even the more complex method that recognizes different types of nonparticipants was unsuccessful. In addition, the estimates of nonparticipation bias are affected by response error, and it is unclear how one might adapt either method to take response errors into account. The consequences of response error for such methods have not been considered systematically in past investigations. Our analyses also suggest that response errors may have serious implications for more rigorous methods of correcting for 
nonparticipation, such as "hot deck" procedures, that impute information taken from participants to nonparticipants (Ford 1983).

It is possible that these methods are not useful here because of the somewhat specialized design and nature of this sample or because of the low response rate, but these methods have been proposed and examined with similarly specialized samples and, despite the response rate, our nonparticipants appear to be somewhat distinct from participants. Although a simple ad hoc method for adjusting for nonparticipation would be welcome, there is little evidence that either of these methods currently provides one. 


\section{APPENDIX A Question Wording}

The Parent Survey used the following questions to determine whether child support was owed in 1986 and the amount of any support owed. Versions shown are those used for custodial parents. The versions for noncustodial parents are exactly parallel.

J.30 Did you and (CHILD)'s (father/mother) have a legal agreement that was in effect during 1986 which specified ANY of (his/her) rights or obligations as a parent, such as custody, rights to see (CHILD), or the obligation to help support (CHILD)?

By "legal agreement" I mean one that has been approved by a judge or another officer of the court.

J.31 ASK IF J.30 = NO. Did you and (CHILD)'s (father/mother) have an informal agreement of this kind that was in effect during 1986 ?

J.59 ASK IF J.30 OR J.31 = YES. Did the agreement you and (CHILD)'s (father/mother) had in 1986 specify that (he/she) provide ANY kind of financial support or health insurance coverage for (CHILD)?

J.62 ASK IF J.59 = YES. The regular payments that parents make for the support of their child(ren) are referred to as child support payments.

The next questions are about child support payments for all of 1986.

According to the agreement you had in 1986, was (CHILD)'s (father/mother) to make REGULAR PAYMENTS, such as every week or every month for (CHILD)'s support?

J.65 ASK IF J.62 = YES. Now, please tell me just about the agreement regarding child support, whether or not you followed it exactly.

According to the agreement that you had during 1986, how much was (CHILD)'s (father/mother) SUPPOSED to pay regularly for (CHILD)'s and (his/her siblings') support?

Do not include other financial help that the child(ren)'s (father/mother) may have agreed to provide for you or the child(ren) in addition to regular support payments.

J.69 How often were the regular child support payments you were supposed to receive missed completely in 1986? In 1986 were all payments missed completely, some payments missed completely, or were all payments made?

(appendix continues) 
APPENDIX A (continued)

J.71 ASK IF J.69 = SOME MISSED. What was the dollar amount of the child support payments that you received in 1986 ?

J.78 ASK IF SOME OR ALL PAYMENTS MADE. Did (CHILD)'s (father/mother) make any part of these payments DIRECTLY TO YOU during 1986?

J.79 In 1986, what was the dollar amount of the payments that you received directly from the (CHILD)'s (father/mother)? 


\section{APPENDIX B}

Number of Cases for Each Figure, by Number of Calls and Number of Telephone Numbers

\begin{tabular}{|c|c|c|c|c|c|c|c|c|c|}
\hline \multirow[b]{2}{*}{ No. of Calls } & \multicolumn{2}{|c|}{ Figure 1: Mothers } & \multicolumn{2}{|c|}{ Figure 2: Fathers } & \multirow{2}{*}{$\begin{array}{l}\text { No. } \\
\text { of Phone } \\
\text { Numbers }\end{array}$} & \multicolumn{2}{|c|}{ Figure 3: Mothers } & \multicolumn{2}{|c|}{ Figure 4: Fathers } \\
\hline & Owed & Paid & Owed & Paid & & Owed & Paid & Owed & Paid \\
\hline 1 & 182 & 184 & 107 & 108 & 1 & 589 & 550 & 413 & 395 \\
\hline 2 & 178 & 180 & 108 & 109 & 2 & 218 & 201 & 223 & 209 \\
\hline 3 & 126 & 128 & 87 & 88 & 3 & 53 & 54 & 77 & 76 \\
\hline 4 & 85 & 86 & 76 & 78 & 4 & 23 & 20 & 18 & 18 \\
\hline 5 & 69 & 70 & 62 & 62 & $5+$ & 18 & 16 & 24 & 23 \\
\hline 6 & 50 & 52 & 37 & 37 & & & & & \\
\hline 7 & 41 & 42 & 31 & 32 & & & & & \\
\hline 8 & 37 & 37 & 30 & 30 & & & & & \\
\hline 9 & 34 & 34 & 33 & 34 & & & & & \\
\hline $10-11$ & 43 & 46 & 43 & 44 & & & & & \\
\hline $12-13$ & 27 & 27 & 31 & 31 & & & & & \\
\hline $14-16$ & 22 & 22 & 39 & 39 & & & & & \\
\hline $17-19$ & 15 & 16 & 24 & 24 & & & & & \\
\hline $20+$ & 35 & 35 & 60 & 61 & & & & & \\
\hline Jonparticipants & 304 & 309 & 446 & 453 & & & & & \\
\hline
\end{tabular}




\section{APPENDIX C \\ Estimates of Means Corrected for Nonparticipation Bias}

In applying the method suggested by Stinchcombe et al. (1981), we retained more categories and detail than they used, to improve the method's chance of success and to take the structure of this

study design into account. Steps 1-8 shown below give the calculations for the estimates in Table 5 . These estimates are comparable to those provided by Stinchcombe et al., except that we distinguish soft and hard temporary refusals. Step 9 describes the adjustment used to obtain the estimates in Table 6. Our description of the steps below refers to the calculations for mothers; the numbers correspond to the calculations shown below.

(1) We calculate the probability of a refusal given that the respondent is located. We add the number of soft temporary refusals, hard temporary refusals, and final refusals to form the numerator; the number of interviewed respondents, temporary refusals, and final refusals are summed to form the denominator. The result, .18 for mothers, for example, is the estimated proportion of all mothers who would refuse the interview at least once.

(2) The model assumes that respondents who are not contacted would, if contacted, respond and refuse in the same proportions observed among those who are contacted. We estimate the proportion of the sample of mothers who are unlocated but who are also potential refusals as .18 multiplied by the proportion of the sample who were unlocated.

(3) Then we subtract the proportion of mothers who are potential refusals from the proportion of unlocated mothers (i.e., .21-.04=.17) to obtain the proportion of the sample who are unlocated but potential respondents.

(4 and 5) The number of temporary refusers who are soft and hard refusals are similar. We divide the potential refusal group into two groups, 2 percent of the whole sample who are unlocated 
but who, once located, would respond as soft temporary refusals do, and 2 percent (i.e., . $04 * .50=.02$ ) who, once located, would respond as hard temporary refusals do.

The proportion of mothers who are easy to locate and are interviewed is .96 (i.e., $848 / 848+39$ ) of the mothers who never refuse; the proportion of the sample who are hard to locate and are interviewed is .01 (i.e., 39/848+39) of the mothers who never refuse.

Therefore, we can divide the potential respondents (17 percent of the whole sample of mothers) into two categories:

(6) 16 percent of the sample would, if located, respond like those who were easy to locate and

(7) 1 percent of the sample who would respond like those who were hard to locate.

(8) These proportions are used to estimate the mean that would have been observed if there had been no nonparticipation: for mothers, 16 percent of the sample have the estimate obtained from the easy to locate respondents (group A); 1 percent have the estimate obtained from the hard to locate respondents (group B); 2 percent have the estimate obtained from the soft temporary refusals (group C); 2 percent have the estimate obtained from the hard temporary refusals (group D).

(9) Adjusted estimates assume that all potential respondents are like those who were difficult to locate. 


\section{APPENDIX C (continued)}

\section{Mothers}

\begin{tabular}{|c|c|c|c|c|c|c|c|}
\hline & $\begin{array}{c}\text { A } \\
\text { Interviewed, } \\
\text { Easy to Locate }\end{array}$ & $\begin{array}{c}\text { B } \\
\text { Interviewed, } \\
\text { Hard to Locate }\end{array}$ & $\begin{array}{c}\text { C } \\
\text { Soft } \\
\text { Temporary } \\
\text { Refusal }\end{array}$ & $\begin{array}{c}\text { D } \\
\text { Hard } \\
\text { Temporary } \\
\text { Refusal }\end{array}$ & $\begin{array}{l}\text { Final } \\
\text { Refusal }\end{array}$ & Unlocated & Total \\
\hline $\mathrm{N}=$ & 848 & 39 & 35 & 37 & 122 & 294 & 1375 \\
\hline $\mathrm{p}=$ & .62 & .03 & .03 & .03 & .09 & .21 & 1.00 \\
\hline
\end{tabular}

(1) $\mathrm{P}($ refuse $/$ locate $)=(35+37+122) /(848+39+35+37+122)=.18$

(2) $.21 * .18=.04$

proportion of total sample who are unlocated and potential refusals

(3) $.21-.04=.17$

(4) $.04 *(35 / 35+37)=.02$ proportion of total sample who are unlocated and potential respondents proportion of total sample who are unlocated and potential refusers similar to soft temporary refusals

(5) $.04 *(37 / 35+37)=.02$ proportion of total sample who are unlocated and potential refusers similar to hard temporary refusals

(6) $.17 *(848 / 848+39)=.16$ proportion of total sample who are unlocated and potential respondents similar to easy-to-locate respondents

(7) $.17 *(39 / 848+39)=.01$ proportion of total sample who are unlocated and potential respondents similar to hard-to-locate respondents

(8) Estimate of mean corrected for nonparticipation bias $=$ $(.62+.16) * \mathrm{~A}+(.03+.01) * \mathrm{~B}+(.03+.02) * \mathrm{C}+(.03+.09+.02) * \mathrm{D}$

(9) Improved estimate of mean corrected for nonparticipation bias = $.62 * \mathrm{~A}+(.03+.17) * \mathrm{~B}+(.03+.02) * \mathrm{C}+(.03+.09+.02) * \mathrm{D}$ 
APPENDIX C (continued)

Fathers

\begin{tabular}{|c|c|c|c|c|c|c|c|}
\hline & $\begin{array}{c}\text { A } \\
\text { Interviewed, } \\
\text { Easy to Locate }\end{array}$ & $\begin{array}{c}\text { B } \\
\text { Interviewed, } \\
\text { Hard to Locate }\end{array}$ & $\begin{array}{c}\text { C } \\
\text { Soft } \\
\text { Temporary } \\
\text { Refusal }\end{array}$ & $\begin{array}{c}\text { D } \\
\text { Hard } \\
\text { Temporary } \\
\text { Refusal }\end{array}$ & $\begin{array}{c}\text { Final } \\
\text { Refusal }\end{array}$ & Unlocated & Total \\
\hline $\mathrm{N}=$ & 651 & 35 & 46 & 45 & 179 & 407 & 1363 \\
\hline $\mathrm{p}=$ & .48 & .03 & .03 & .03 & .13 & .30 & 1.00 \\
\hline
\end{tabular}

(1) $\mathrm{P}$ (refuse $/$ locate $)=(46+45+179) /(651+35+46+45+179)=.28$

(2) $.30 * .28=.08$

proportion of total sample who are potential refusals among those unlocated

(3) $.30-.08=.22$ proportion of total sample who are potential respondents among those

(4) $.08 *(46 / 46+45)=.04$ unlocated

(5) $.08 *(45 / 46+45)=.04$ proportion of total sample who are unlocated and potential refusers similar to soft temporary refusals

(6) $.22 *(651 / 651+35)=.21$ proportion of total sample who are unlocated and potential refusers similar to hard temporary refusals

(7) $.22 *(35 / 651+35)=.01$ proportion of total sample who are unlocated and potential respondents similar to easy-to-locate respondents proportion of total sample who are unlocated and potential respondents similar to hard-to-locate respondents

(8) Estimated mean corrected for nonparticipation bias $=$ $(.48+.21) * \mathrm{~A}+(.03+.01) * \mathrm{~B}+(.03+.04) * \mathrm{C}+(.03+.13+.04) * \mathrm{D}$

(9) Improved estimated mean corrected for nonparticipation bias = $.48 * \mathrm{~A}+(.03+.22) * \mathrm{~B}+(.03+.04) * \mathrm{C}+(.03+.13+.04) * \mathrm{D}$ 


\section{Notes}

${ }^{1}$ Another application of models of the relationship between participants and nonparticipants is to identify the point at which further field efforts become unnecessary because sample estimates no longer change when additional sample members are interviewed (for a discussion, see e.g., Groves 1989). These applications are aimed primarily at evaluating survey costs and fall outside the scope of this paper.

${ }^{2}$ In this study, resident parents are those with physical custody. Physical custody is defined as living with the children for at least six months in 1986. The mother is the resident parent in the large majority of divorce cases.

${ }^{3}$ Because the distributions of the amount of child support owed and paid are positively skewed, we also conduct analyses and significance tests using the natural logarithms of these variables. One was added before taking the natural logarithms because of the number of zeros. Results for the proportion of mothers owed or paid any support can be found in Lin (1990).

${ }^{4}$ The impact of response error is considered more fully below in the discussion of the classes model.

${ }^{5}$ All nonparticipants include final refusers and unlocated mothers.

${ }^{6}$ Until a respondent is located, we cannot distinguish a failure to contact from a failure to locate. We consider all calls made before the parent's location was confirmed as locating calls. Only three parents whose location was confirmed were not contacted at the end of the field period.

${ }^{7} \mathrm{We}$ also examined this relationship using the indicators described in the previous section. For both mothers and fathers, the probability of locating the parent generally increases as the total number of calls and the number of calls to the last telephone number increase (data not shown). Although these relationships appear to be fairly smooth, leveling off after approximately eight calls, we have 
already seen (Figure 1 and Figure 2) that there is no clear relationship between either indicator and the mean amounts of child support owed or paid.

${ }^{8}$ For mothers, eta squared for child support owed and paid is very small both in the PS (.02 for owed and paid) and the CRD (.01 for owed; .02 for paid). Thus, the linear relationship between the number of telephone numbers and the payment variables is even smaller. The relationship is also weak for fathers in the PS and the CRD (eta is .02 for both owed and paid).

${ }^{9}$ Although previous applications of this model have not examined whether such groups differ significantly from each other, we tested the results of this decision using the Bonferroni method of multiple comparisons. Classifying those for whom more than three numbers were called as hard-to-locate and analyzing the PS--to which an investigator applying the model would be restricted--we found that the mean child support owed or paid to hard-to-locate mothers or fathers does not differ significantly from that owed or paid to easy-to-locate mothers or fathers ( $>$ >.20). The results are the same if one examines the CRD. See Table 4 below.

${ }^{10}$ Although we recognize that there may be considerable interviewer variability in the use of the two refusal categories, we preserve them because differences among types of refusals are potentially important. Respondents who ever refused are classified in the "temporary refusal" categories, regardless of whether they were easy or difficult to locate. It is not clear which classification should take priority, and this rule may increase the heterogeneity of the refusal categories, but the refusers are similar to the easy-to-locate in the number of different telephone numbers required for location, providing some support for this decision.

${ }^{11}$ It does not seem that the different patterns for mothers and fathers arise only because of a few outliers. If outliers are omitted some of the patterns in this table do become more similar for mothers and fathers, but other patterns become more dissimilar. 
${ }^{12}$ The tests performed using logs of the amounts owed and paid give the same results as those presented in Table 4 with the two exceptions noted in the text and with the following additional exceptions: As the model suggests, final refusers and unlocated fathers differ significantly for support owed in the CRD ( $\mathrm{p}<.01)$; contrary to the model's assumptions, the unlocated and hard-to-locate fathers differ significantly for support owed $(\mathrm{p}<.05)$ and paid $(.05<\mathrm{p}<.10)$ in the CRD; and the hard temporary and soft temporary refusals differ significantly for fathers for support paid in the PS $(.05<\mathrm{p}<.10)$

${ }^{13}$ The difference between the mean for the total sample and the mean for the "population" of CRD cases from which the sample was drawn is trivially small (i.e., approximately four dollars for support owed and forty dollars for support paid; see Schaeffer et al. [1991]). We ignore this sampling variability in the discussion because it would complicate the presentation without affecting the conclusions.

${ }^{14}$ According to the CRD, the percentages with no child support owed for final refusals, hard temporary refusals, soft temporary refusals, easy-to-locate participants, hard-to-locate participants, and unlocated nonparticipants are 8.2, 10.8, 11.4, 7.7, 12.8, and 17.0 for mothers. The comparable percentages for fathers are $7.3,8.9,8.7,6.9,5.7$, and 17.7. The comparable percentages for mothers with no child support paid are 33.6, 27.0, 34.3, 32.3, 43.6, and 49.7. For fathers, the proportions with no child support paid are $36.9,31.1,43.5,29.5,28.6$, and 48.5 . 


\section{References}

Bartfeld, Judi. 1991. "Parent Survey 2: Field Report." Unpublished manuscript. Child Support Demonstration Project, Institute for Research on Poverty, University of Wisconsin-Madison.

Duncan, Greg, and Nancy A. Mathiowetz. 1985. A Validation Study of Economic Survey Data. Ann Arbor, Michigan: Institute for Survey Research.

Dunkelberg, William C., and George S. Day. 1973. "Nonresponse Bias and Callbacks in Sample Surveys." Journal of Marketing Research 10: 160-168.

Ellis, Robert A., Calvin M. Endo, and J. Michael Armer. 1970. "The Use of Potential Nonrespondents for Studying Nonresponse Bias." Pacific Sociological Review 13: 103-109.

Filion, F. L. 1976. "Exploring and Correcting for Nonresponse Bias Using Follow-ups of Nonrespondents." Pacific Sociological Review 19: 401-408.

Fitzgerald, Robert, and Linda Fuller. 1982. "I Hear You Knocking but You Can't Come In: The Effects of Reluctant Respondents and Refusers on Sample Survey Estimates." Sociological Methods and Research 11: 3-32.

Ford, Barry L. 1983. "An Overview of Hot-Deck Procedures." In Incomplete Data in Sample Surveys, Volume 2, Theory and Bibliographies, ed. William G. Madow, Ingram Olkin, and Donald B. Rubin, pp. 185-207. New York: Academic.

Groves, Robert M. 1983. "Discussion." In Incomplete Data in Sample Surveys, Volume 3, Proceedings of The Symposium, ed. William G. Madow and Ingram Olkin, pp. 61-63. New York: Academic. . 1989. Survey Errors and Survey Costs. New York: John Wiley \& Sons.

Hawkins, Darnell F. 1975. "Estimation of Nonresponse Bias." Sociological Methods and Research 3: $461-485$. 
Lin, I-Fen. 1990. "Using Respondents as Proxies to Estimate the Characteristics of Nonrespondents." Unpublished Master's thesis, Department of Sociology, University of Wisconsin-Madison.

Madow, William G., Ingram Olkin, and Donald B. Rubin, eds. 1983. Incomplete Data in Sample Surveys, Volume 2, Theory and Bibliographies. New York: Academic.

Neter, John, William Wasserman, and Michael H. Kutner. 1989. Applied Linear Regression Models. Boston: Irwin.

O’Neil, Michael J. 1979. "Estimating the Nonresponse Bias Due to Refusals in Telephone Surveys." Public Opinion Quarterly 43: 218-232.

Platek, R., M. P. Singh, and V. Tremblay. 1978. "Adjustment for Nonresponse in Surveys." In Survey Sampling and Measurement, ed. N. Krishnan Namboodiri, pp. 157-174. New York: Academic.

Schaeffer, Nora Cate. In press. "Errors of Experience: Response Errors in Reports about Child Support and Their Implications for Questionnaire Design." In Autobiographical Memory and the Validity of Retrospective Reports, ed. Norbert Schwarz and Seymour Sudman. New York: Springer-Verlag.

Schaeffer, Nora Cate, Judith A. Seltzer, and Marieka Klawitter. 1991. "Estimating Nonresponse and Response Bias: Resident and Nonresident Parents' Reports about Child Support." Sociological Methods and Research 20(1): 30-59.

Smith, Tom W. 1984. "Estimating Nonresponse Bias with Temporary Refusers." Sociological Perspectives 27: 473-489.

Stinchcombe, Arthur L., Calvin Jones, and Paul Sheatsley. 1981. "Nonresponse Bias for Attitude Questions." Public Opinion Quarterly 45: 359-379. 
Thomsen, Ib, and Erling Siring. 1983. "On the Causes and Effects of Nonresponse: Norwegian Experiences." In Incomplete Data in Sample Surveys, Volume 3, Proceedings of The Symposium, ed. William G. Madow and Ingram Olkin, pp. 25-59. New York: Academic.

Traugott, Michael W. 1987. "The Importance of Persistence in Respondent Selection for Preelection Surveys." Public Opinion Quarterly 51: 48-57. 